\title{
Task-oriented reading efficiency: interplay of general cognitive ability, task demands, strategies and reading fluency
}

\author{
Jarkko Hautala ${ }^{1,6}$ (D) Ladislao Salmerón ${ }^{2} \cdot$ Asko Tolvanen $^{3} \cdot$ Otto Loberg $^{4}$. \\ Paavo Leppänen ${ }^{5,6}$
}

Accepted: 1 February 2022 / Published online: 24 February 2022

(c) The Author(s) 2022

\begin{abstract}
The associations among readers' cognitive skills (general cognitive ability, reading skills, and attentional functioning), task demands (easy versus difficult questions), and process measures (total fixation time on relevant and irrelevant paragraphs) was investigated to explain task-oriented reading accuracy and efficiency (number of scores in a given time unit). Structural equation modeling was applied to a large dataset collected with sixth-grade students, which included samples of dysfluent readers and those with attention difficulties. The results are in line with previous findings regarding the dominant role of general cognitive ability in the accuracy of task-oriented reading. However, efficiency in task-oriented reading was mostly explained by the shorter viewing times of both paragraph types (i.e., relevant and irrelevant), which were modestly explained by general cognitive ability and reading fluency. These findings suggest that high efficiency in task orientation is obtained by relying on a selective reading strategy when reading both irrelevant and relevant paragraphs. The selective reading strategy seems to be specifically learned, and this potentially applies to most students, even those with low cognitive abilities.
\end{abstract}

Keywords Information literacy $\cdot$ Task-oriented reading $\cdot$ Eye movements $\cdot$ Reading efficiency $\cdot$ Learning disabilities

Jarkko Hautala

jarkko.hautala@nmi.fi

1 Niilo Mäki Institute, Asemakatu 4, FI-40014 Jyväskylä, Finland

2 Department of Developmental and Educational Psychology, University of Valencia, Valencia, Spain

3 Faculty of Education and Psychology, University of Jyväskylä, Jyväskylä, Finland

4 Department of Psychology, Bournemouth University, Bournemouth, UK

5 Department of Psychology, University of Jyväskylä, Jyväskylä, Finland

6 Centre for Interdisciplinary Brain Research, University of Jyväskylä, Jyväskylä, Finland 


\section{Introduction}

Finding relevant information swiftly is a basic task-oriented reading skill. Most research has focused on explaining accuracy in task-oriented reading with adult participants (e.g., OECD, 2019; Rouet, 2006; Rouet et al., 2017; Snow, 2002; VidalAbarca et al., 2011). However, there is an emerging interest in understanding efficient reading strategies (Soederberg Miller, 2009; León et al., 2019) and in how students' various cognitive skills (e.g., reading fluency) define their processes and outcomes in purposeful reading (for reviews, see Anmarkrud et al., 2018; Ben-Yehudah et al., 2018).

In the current study, we analyzed how adolescents find an answer to an informational task on a well-structured page. Our focus was identifying the generic processes and cognitive foundations that underlie accuracy (i.e., scores) and efficiency (i.e., task score divided by time spent on task) in task-oriented reading skills.

\section{Task-oriented reading}

Task-oriented reading is the ability to read one or more texts to achieve a specific goal (Vidal-Abarca et al., 2010). Essential to task-oriented reading is text relevance, which pertains to the sections of a text that include information useful for completing the reading task. This differs from text importance, which is related to which parts of a text are necessary to fully understand that text (McCrudden \& Schraw, 2007).

The Task-based Relevance Assessment and Content Extraction (TRACE) model attempts to specify the process of task-oriented reading (Rouet, 2006). This model identifies a sequence of crucial steps, starting with understanding of the task demands (Cerdán et al., 2019; Tawfik et al., 2020), then constructing a task model, followed by gathering information from the text to create a document model. Readers must continue to search for and focus on relevant information, discard irrelevant information, and determine when sufficient information has been gathered to solve the task. This procedure is believed to be conceived of as a series of complex cycles in which the previous steps determine how subsequent steps are implemented (Rouet, 2003).

In accordance with the TRACE model, people are found to put effort into the proper construction of the task model. They spend more time reading difficult questions than easy questions (Martínez et al., 2009) and questions that demand a global understanding of a text rather than a local one (McCrudden et al., 2010; Rouet et al., 2003; Cerdán et al., 2009).

Concerning the construction of the document model, people generally spend longer reading relevant sections than irrelevant sections (McCrudden \& Schraw, 2007). Relevant parts of a text are also returned to more often or for a longer period of time (Yeari et al., 2015; see also Hautala et al., 2019; Kaakinen et al., 2015), which presumably indicates the prolonged semantic processing of that content. A larger relevancy effect is associated with better accuracy in task-oriented reading (e.g., higher scores on comprehension questions; Hautala et al., 2019; Salmerón 
et al., 2017). More general questions may induce more time spent reading the document (Rouet, 2003), yet null effects have also been reported (Cerdán et al., 2009; Rouet et al., 2001; Salmerón et al., 2017). However, these studies have probably differed in the difficulty of locating specific answers from complex hypertexts or multiple documents used in the studies. Eye-movement studies suggest that a specific goal induces readers to be more selective in their reading than when reading for general comprehension, spending more time viewing relevant content and less time viewing irrelevant content in the former case (León et al., 2019; McCrudden \& Schraw, 2007). Overall, when the task is more difficult (e.g., why-vs. what- questions, general vs. specific, or integrate vs. locate), readers seem to spend more time detecting, locating and/or reading the relevant parts of the text (Rouet, 2003; Rouet et al., 2001).

Focusing on relevant information may also contribute to task efficiency, which is a neglected aspect of reading comprehension and task-oriented reading research (Soederberg Miller, 2009). The concept of efficiency can be incorporated into current theoretical views (Stine-Morrow et al., 2006; Britt et al., 2017). Accordingly, readers allocate attention to a text in a way that enables them to construct a representation of the passage that is "good enough" to achieve their current reading goals and relative to their abilities and other situational factors. However, to our knowledge, Soederberg Miller (2009) is the only study of reading efficiency in the context of a text recall task (i.e., the amount of information recalled from each paragraph). Soederberg Miller found that efficiency was correlated with accuracy at the 0.6-0.7 level and with reading time at the $0.4-0.6$ level, providing evidence that efficiency is a sufficiently separate aspect from accuracy and speed. This is already the case for a task that requires only a rudimentary level of reading comprehension.

One potential way to attain high efficiency in task-oriented reading is to rely on a selective reading strategy (León et al., 2019), i.e., by trying to read only relevant parts of text. Selective reading strategies can be supported by informative headings, which have been shown to facilitate performance in search tasks (Lorch et al., 2011). In principle, in search tasks with informative headings, readers may strategically select to read only the relevant paragraph. However, selectivity may also manifest more generically, for example, by continuously adapting reading depth according to text relevance (Yeari et al., 2015). Given that even relevant paragraphs also contain less relevant parts, efficiency may be explained by shorter reading times for both relevant and irrelevant paragraphs.

\section{Foundation for task-oriented reading}

According to Britt et al. (2017), readers' cognitive resources (or skills) provide a foundation for individuals' purposeful reading comprehension abilities. Cognitive skills are intercorrelated to the extent that the concept of general cognitive ability is justified (Jensen, 1998). High general cognitive ability indicates that a student can master diverse types of tasks given through verbal instructions and can therefore be assumed to exhibit high control over his or her reading behaviors (Rouet, 2003, 2006). General cognitive ability may support comprehension, e.g., via an increased 
ability to conduct more fine-grained inferences between multiple text elements (Moehring et al., 2016).

General cognitive ability is thought to be captured by the first-order factor of performance in cognitive assessments, operationally defined as the g-factor (Jensen, 1998), on which reading and literacy skills (Alloway \& Gregory, 2013; Rindermann, 2007; Wolf et al., 2012) and executive and working memory functions (Packwood et al., 2011) are strongly loaded. The g-factor is influenced by genetic and environmental factors, among which the child's parental language proficiency and educational level are the most influential (Hart \& Risley, 1995). The g-factor is also a relevant concept for understanding learning disabilities, which are typically accompanied by lower levels of performance in several cognitive skills (Laasonen et al., 2020).

In a previous study, $83 \%$ of adults' accuracy in a multiple-choice task-oriented reading task was explained using fluid and crystallized intelligence measures (Moehring et al., 2016). In a different study, when controlling for reading fluency and comprehension, a nonverbal reasoning measure, the Raven Standard Progressive Matrices (RSPM), explained only 14\% of adolescents' scores in a complex taskoriented reading task requiring the writing of summaries (Kanniainen et al., 2019).

More research with a diverse set of predictors is needed to unravel the extent to which task-oriented reading relies on general cognitive ability on the one hand and on residual variance in specific skills on the other. These specific skills may also be more malleable than general cognitive ability and thus deserve the most instructional effort in education (Kempe et al., 2011; Stuebing et al., 2009).

The strongest candidate for a specific skill that can explain task-oriented reading is one's reading comprehension skill, defined as the ability to identify the main information in a text and to use inferences and prior knowledge to gain a complete understanding of it (Cataldo \& Oakhill, 2000; Salmerón et al., 2015, 2017, 2018; Sung et al., 2015; Vidal-Abarca et al., 2010). Evidence indicates that high comprehenders perform more accurately than low comprehenders in task-oriented reading tasks (Cataldo \& Oakhill, 2000; Salmerón et al., 2015, 2017, 2018; Sung et al., 2015; Vidal-Abarca et al., 2010). High comprehenders are more selective in their reading, they spend relatively less time reading irrelevant paragraphs to answer more challenging questions, with no difference observed in easier questions (Salmerón et al., 2017). They also spend extra time reading important topic sentences (Sung et al., 2015).

Poor attention skills have also been associated with difficulties in task-oriented reading (Ben-Yehudah \& Brann, 2019; Hautala et al., 2019; Stern \& Shalev, 2013). Utilizing eye-tracking methodology, Hautala et al. (2019) found that in reading task assignments, poor reading fluency was associated with overall longer first-pass reading times for sentences, whereas attention problems were associated with a lower probability of making selective look-backs specifically at relevant sentences (Hautala et al., 2019). The results were interpret to indicate that attentional problems impair comprehension monitoring. Additionally, poor reading fluency may limit the attention resources available for comprehension processes (Kanniainen et al., 2019). Poor readers have consistently been found to rely more on external cues, such as text highlighting, than typical readers (Bar-Zvi Shaked et al., 2020). 
Research has produced somewhat mixed results concerning the importance of prior knowledge in task-oriented reading (Coiro, 2011; Cromley \& Azevedo, 2009; Moehring et al., 2016; (Rouet, 2003; Soederberg Miller, 2009). Efficiency in a reading recall task has been explained rather poorly by age and working memory (Soederberg Miller, 2009), suggesting that efficiency relies mostly on a reader's learned competence.

Overall, research suggests that task demands, reading strategies, and cognitive skills contribute to task-oriented reading, yet they are seldom studied together. From a theoretical perspective, the lack of such studies limits our understanding of the generic processes underlying task-oriented reading. From a pedagogical perspective, this situation limits our ability to provide appropriate support to students with taskoriented reading difficulties.

\section{The current study}

In this study, we aimed to explicate the relationships between the g-factor and selective reading strategy in explaining accuracy and efficiency in task-oriented reading. Students whose reading and attention skills ranged broadly (Anmarkrud et al., 2018; Ben-Yehudah et al., 2018) were asked to locate and verbally report the answers to easy and difficult questions that contained irrelevant and relevant paragraphs presented on a computer screen while their eye movements were recorded. Note that in the framework of the TRACE model, the present investigation is limited to the subprocess of document model construction.

While most previous research has been concerned with testing conditional differences in group averages, our study used structural equation modeling (SEM) to model the direct and mediated associations of cognitive skills to a reading process (conceptualized as time spent viewing irrelevant and relevant paragraphs) and to accuracy and efficiency outcomes. The students were expected to be selective in their reading and thus spend more time reading relevant paragraphs than irrelevant ones. However, this selective reading strategy may manifest both in strategically selecting which paragraph to read or as a more generic process of spending less time reading regardless of a paragraph's relevancy. Regarding different performance aspects, high accuracy may be obtained with a thorough reading of both paragraphs, whereas high efficiency may require the use of a selective reading strategy. These effects of reading strategy should appear even when statistically controlling for reading fluency, which is expected to strongly explain fixation times.

Previous studies have not studied diverse sets of cognitive skills in conjunction with each other; therefore, it is not clear whether task-oriented reading relies mostly on general cognitive ability or, for instance, on attention or reading skills. Another novel aspect of the present study is to analyze both accuracy and efficiency (Soederberg Miller, 2009) in task-oriented reading. Because high accuracy may be obtained regardless of the reading strategy used, cognitive skills may directly explain accuracy, whereas viewing times may mediate the effect of cognitive skills on efficiency.

On the other hand, task difficulty may induce multidimensionality in both process and outcome measures. Multidimensionality means that while most variability is 
shared between easy and difficult questions, there may also be a significant amount of unique variability in each task type, which may have a specific association with other measures. Obtaining high accuracy in answering difficult questions may be more dependent on one's general cognitive ability or reading comprehension than is the case when answering easier questions.

\section{Method}

\section{Participants}

This study's participants were involved in the neurocognitive substudy of the eSeek research project focusing on internet reading skills in a large inclusive sample of 426 sixth-grade students (Kiili et al., 2018). To more closely study the possible unique influences of learning difficulties (e.g., reading dysfluency, attention difficulties, and their comorbidity), representative students, along with many randomly selected control students, from the classroom study were screened. The 164 sixth-grade participants (age $M=12$ years 4.2 months, $S D=3.7$ months; 98 boys and 66 girls) were thus invited to take individual cognitive assessments and eye-tracking measurements in the laboratory setting as a subsample. The specific inclusion and exclusion criteria for each measure are given in the 7 section below, and the number of participants in each recruitment group is given in Table 1. The eye-tracking measurement failed with three students, whose data were thus excluded from the analysis. In accordance with the Declaration of Helsinki, we obtained written consent from all students and their guardians before the study. Ethical approval for this study was received from the ethics board of the University of Jyväskylä.

\section{Measures}

The maximum scores, observed means, and standard deviations are given in Table 1.

Attention difficulties were assessed using a 55-item Attex attention-deficit questionnaire (internal reliability of Cronbach's $=0.95$ ) completed by the teachers (Klenberg et al., 2010) as a part of the classroom study. All students who scored higher than the 75 th standardized percentile (17 points) were invited to participate in the individual assessment study. Higher scores indicated greater attention problems. Depending on their performance in the reading fluency screening tasks, these students were assigned either an attention difficulty or a comorbid group status (see Table 1).

Reading fluency was assessed using three tasks: a word identification task (Lindeman, 1998), pseudoword text reading (Eklund et al., 2015), and a word chain segmentation test (Holopainen et al., 2004). It should be noted that both lexical and word decoding processes are important in reading Finnish (Eklund et al., 2015). The reading fluency factor was extracted from the performance of these three tests by principal axis factoring with promax rotation (SPSS). All students below the 15th percentile in reading fluency were invited to participate in the study. Depending on 
their scores on the Attex task, these participants were assigned either a difficult or a comorbid group status (see Table 1).

The RSPM (Raven, 1998) is a nonverbal reasoning task. A shortened version containing 30 items was used; these items comprised every second item from the larger test (Wytek et al., 1984) and Cronbach's $=0.81$ for these items (Kanerva et al., 2019). To exclude the possibility that very low general cognitive ability would affect the results, students performing lower than the 7th percentile (approximately 16 points) in the classroom sample were not invited to participate in this study.

The visual attention task (NEPSY-II: Korkman et al., 2008) requires a participant to scan an A3 sheet and mark specified visual targets among several similar distractors (e.g., face drawings). The score equals the number of correct responses minus the number of incorrect responses given within three minutes.

The symbol search task (WISC-IV: Wechsler, 2003) measures several functions of visuospatial attention. The participant must search for target symbols from a search group with a two-minute time limit. The score equals correct minus incorrect responses.

The animal sorting task (NEPSY-II: $=0.54)$ measures concept formation, the ability to apply concepts, and set-shifting. The task requires participants to sort cards into two groups of four cards each using various self-initiated sorting criteria. The score equals the number of correct responses.

The block design task (WISC-IV: = 0.91) measures a child's ability to analyze and synthesize abstract visual stimuli. The task requires a participant to recreate a displayed model by using red-and-white blocks within a 45 -second time limit. The score equals the number of correct responses.

The memory for designs, immediate and delayed task (NEPSY-II: test-retest = 0.87 ) assesses visuospatial memory. The participant must remember a series of nonfigural abstract shapes and their positions on a grid. In immediate or delayed recall conditions, the participant is asked to select target shapes from a set of cards and position them on an empty grid. The score equals the sum of points derived from fully correct (two points) or partially correct responses (one point).

The word list interference task (NEPSY-II: $=0.76$ ) assesses verbal working memory, repetition, and word recall following interference. The participant is presented with two lists of words and then asked to repeat each list. Then, the participant is asked to recall each list in the order it was presented. The scoring takes into account partially correct responses.

The digit span task (WISC-IV: $=0.80$ ) assesses short-term and working memory by requiring participants to repeat a list of digits spoken by an instructor in the same or reverse order that it was presented in. The score equals the sum of correct responses.

Reading comprehension (Lindeman, 1998) was assessed with one subtask from a standardized reading test (Cronbach's $=0.64$; Revelle's $=0.86$ ) administered as a group test in the classroom study. Participants read an expository text (instructions for consumers) and responded to 12 multiple-choice questions (four options) that represented the followed categories: (1) detail/fact (one question); (2) cause-effect/ structure (one question); (3) conclusion/interpretation (four questions); (4) concept/ phrase (three questions); and (5) main idea/purpose (three questions). The two-page 
text was available to participants when responding to the questions. The maximum score was 12 points.

The rapid naming task (RAN: Denckla \& Rudel, 1976) assesses the automatization of the sequential naming of familiar items. The child names a matrix of randomly ordered items aloud from a set of five items. Both letter and object subtasks were administered.

The vocabulary task (WISC-IV, $=0.96$ ) measures a child's word knowledge and verbal concept formation by requiring the child to name the pictures in a stimulus book. For the verbal items, the child must give definitions for the words the examiner reads aloud. The score equals the sum of the points for each item $(0,1,2)$.

\section{Information search experiment}

First, self-evaluated prior knowledge on the topics covered in the information search experiment was assessed using a self-rating scale (e.g., "How much do you know about the threats to coral reefs?") administered on a sheet of paper before the experiment. The answer choices were as follows: (1) I know nothing (38.1\% of responses); (2) I know very little (30.5\% of responses); (3) I know a little (20.8\% of responses); (4) I know a fair amount (9.4\% of responses); and (5) I know a lot about the subject (1.3\% of responses). Because of the small number of responses indicating high prior knowledge, categories 3-5 were combined to achieve an evenly distributed threecategory scale. Reliability across the 10 tasks was $\alpha=0.68$.

Then, the students, without a time limit, completed 10 tasks that simulated searching for information on the internet. Each task consisted of a sequence of subtasks: (1) reading a four-line text specifying the task assignment; (2) selecting a search query from among five alternatives; (3) selecting a search result from among four alternatives; (4) reading a static webpage where the answer was located at either the beginning or at the end of a relevantly titled paragraph, which was one of the two paragraphs presented on the screen (see Fig. 1); and (5) reporting the answer verbally to a research assistant after leaving the webpage. Short instruction prompts guided the students through the sequence (e.g., "Good work. Next, choose the most appropriate search query for the given information search problem.”).

To ensure that even the lowest-performing students could complete the tasks, the critical task assignment sentence was repeated on an instruction screen immediately before entering the webpage. To provide some thematic continuation in the lengthy experiment, two adjacent tasks always shared a common theme. Only eye movements during the fourth subtask (i.e., the webpage screen; see Fig. 1) are investigated in this present paper.

Five of the tasks involved 'easy' questions that required finding a single fact, whereas five of the tasks involved 'difficult' questions; correct answers consisted of two aspects placed successively in the text within the relevant paragraph. The placement of easy and difficult questions in the experiment, the position of the relevant paragraph (upper or lower), and the answer location within the relevant paragraph varied in a fixed pseudorandom order, thus being equivalent for each participant. To enable the effective use of task-oriented reading strategies, the paragraph's relevancy for the information search 


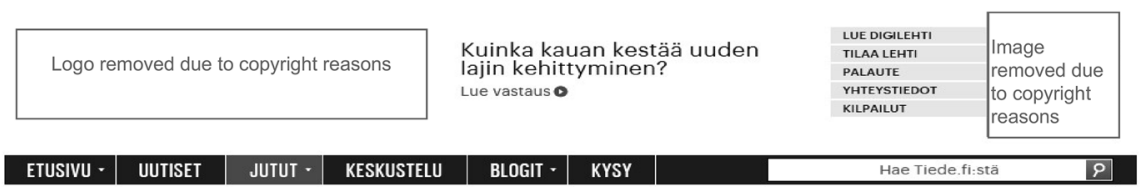

Mitä lumelääkkeellä tarkoitetaan?

Lumelääke tarkoittaa aidolta lääkkeeltä vaikuttavaa valmistetta, josta on kuitenkin poistettu varsinainen lääkeaine. On nimittäin havaittu että pelkällä lumelääkkeelläkin on terveyttä ja toipumista edistäviä vaikutuksia. Uusilta lääkkeiltä vaaditaan suurempaa tehoa kuin lumelääkkeeltä. Jotta lääke saisi Suomessa myyntiluvan, sen on osoitettava helpottavan sairauden oireita lumelääkettä paremmin vähintään kahdessa tutkimuksessa. Lain mukaan tutkimukseen osallistuville on kerrottava, että osa tutkittavista saa pelkkää lumelääkettä. Yleensä noin 30-40 prosenttia lumeryhmän potilaista ilmoittaa oireidensa lievittyneen lääkekokeilun aikana.

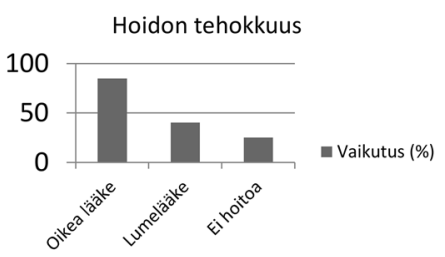

Miten lumelääke oikein vaikuttaa?

Osa lumevaikutuksesta selittyy inmisten taipumuksella antaa miellyttäviä vastauksia. Vaikutus on suurimmillaan myös silloin, kun potilaat luulevat nauttivansa oikeaa lääkettä. Lumelääke helpottaa potilaiden oloa silloinkin kun potilas tietää saavansa lumelääkettä. Tämä saattaa johtua hoidon aktivoivasta vaikutuksesta. Osa lumelääkkeen tehosta johtuu ajan kuluessa tapahtuvasta luonnollisesta toipumisesta. Lumevaikutuksen kokeminen ei näytä riippuvan kokijan persoonallisuudesta. Lumelääkkeiden vaikutus on kasvanut viime vuosikymmeninä. Tähän on tarjottu selitykseksi muun muassa sitä, että ihmisten usko lääkkeiden tehoon olisi parantunut.

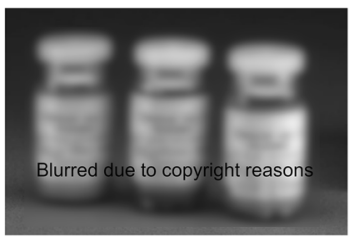

Fig. 1 Example of a stimulus screen

task was cued by the semantic content of the paragraph titles. Lengthy paragraphs were used to induce a high benefit of the selective reading strategy on task efficiency.

The accuracy of the students' responses was determined by audio recording their verbal answers, which were transcribed and scored by trained research assistants according to predefined criteria for accurate responses. The easy questions were scored as 0 or 1 , and the difficult questions were scored as 0,1 , or 2 , corresponding to the number of correct aspects of the student's answer. For example, for the difficult question 'What is a placebo?', the aspects were (a) a product resembling genuine medicine, (b) out of which the effective substance has been removed. The interrater reliability of the scores of the verbal responses was high $(\alpha=0.95)$ in a random sample of 20 participants (i.e., 200 responses). Time-on-task values - the time (sec) a student viewed the screen-were derived from the eye tracker's result files. Information search efficiency was calculated by dividing the score in a trial by the corresponding time-on-task values.

The assignment for this task stated, "Find out what the placebo means in medicine." The relevant paragraph was hinted at by the overall title, "What is a placebo?", whereas the title of the irrelevant lower paragraph was "How does a placebo exert its influence?"

\section{Apparatus}

The students' eye movements were measured using a table-mounted EyeLink 1000 eye tracker (SR Research). To achieve the high spatial accuracy of the eye-movement recordings, each student's head was stabilized using a chin rest and forehead 

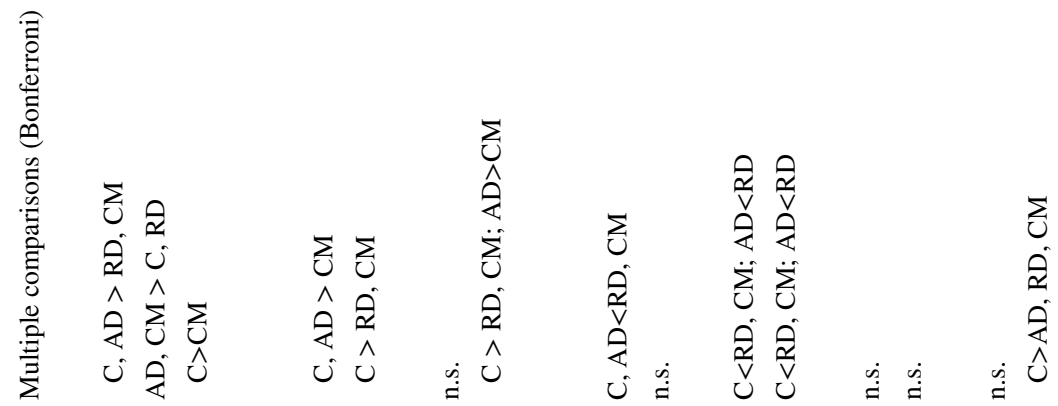

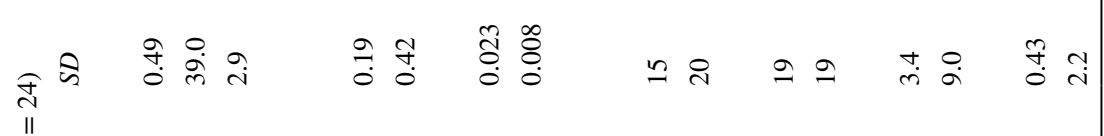

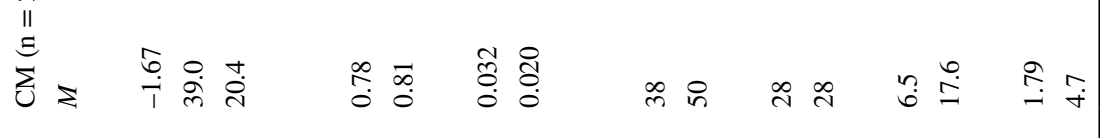
तิ के

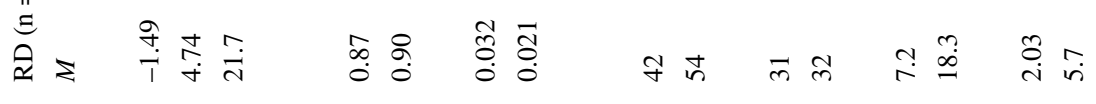

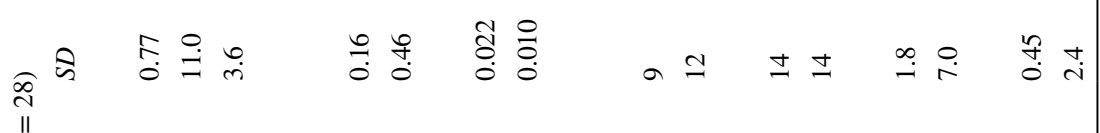

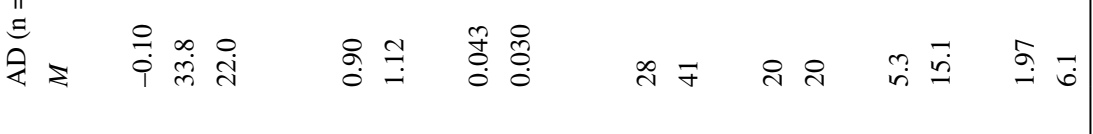




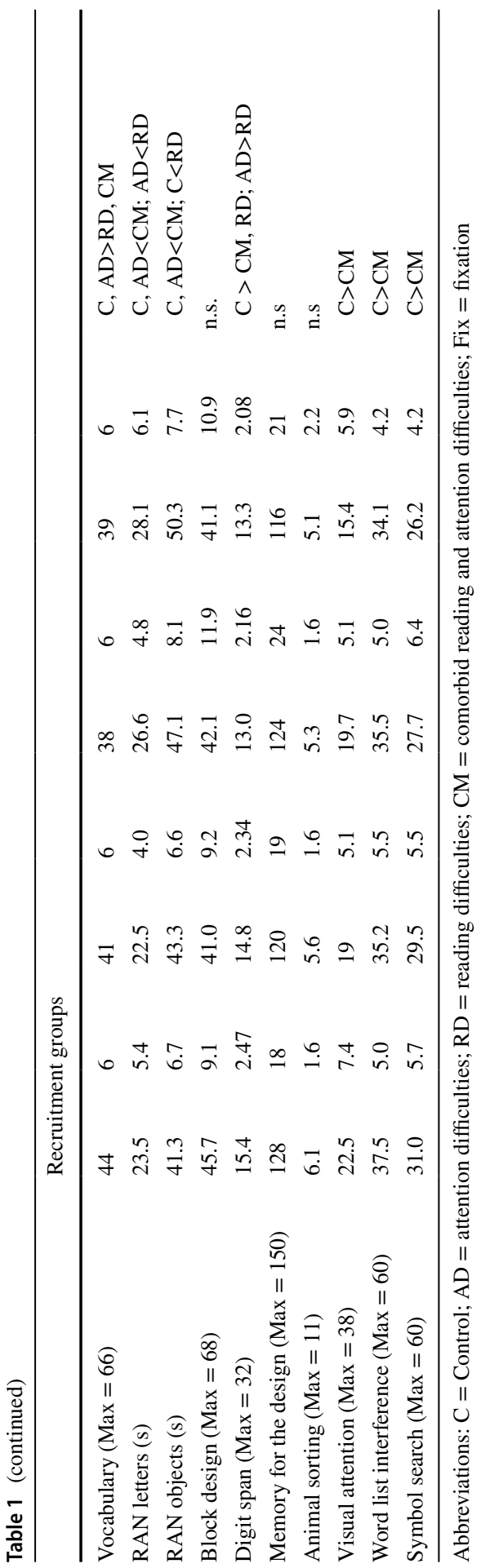


rest. The stimuli were presented on a Dell Precision T5500 workstation with an Asus VG-236 $(1920 \times 1080,120 \mathrm{~Hz}, 52 \times 29 \mathrm{~cm})$ monitor. The participants viewed the stimuli at a distance of $60 \mathrm{~cm}$. Calibration was performed using a 13-point grid with 1 degree visual angle as the acceptance criterion. The calibration was conducted before the experiment and then repeated between trials when visible head movements were made when drift was observed on the researcher's screen or when the calibration-validation error exceeded 0.30 visual degrees.

\section{Procedure}

One research assistant worked with the students in the measurement room, while another assistant controlled the measurement devices in the control room. The students first completed the self-evaluated prior knowledge questionnaire on paper. The information search task was then introduced with a practice task on paper with a research assistant. Next, the table height and the forehead rest of the eye-tracking system were adjusted. The eye tracker was calibrated, and the students completed one practice task using a computer mouse. During each task sequence, the students were required to make only a couple of mouse-controlled selections with no time limit and low requirements for spatial accuracy. The students then completed the experiment, taking one or fewer breaks depending on their needs. The calibration was repeated after each break. Each experimental session lasted 45-90 min, depending on the student. The students were instructed to complete the tasks as accurately and quickly as possible.

\section{Eye-movement data processing}

Fixations and saccades were identified according to the criterion of 30 degrees per second using the DataViewer program (SR Research). We analyzed only the total fixation time for the irrelevant and relevant paragraphs, including their titles, and for the answer area.

Eye-movement data contain spatial errors (offset), which can be reliably reduced by manual correction based on visual inspections (Cohen, 2013). The trained research personnel were unaware of the hypotheses of this study and the students' abilities. They visually inspected the eye-tracking data to exclude screens with poorquality eye-tracking data that could not be remedied (i.e., $2.6 \%$ of the screens in the experiment). The researchers also manually repaired systematic offsets in fixation locations on the vertical axis where fixations fell on the wrong side of the area-ofinterest (AOI) boundary. This repair was conducted for $56 \%$ of the webpage viewing screens, which affected $17.4 \%$ of the fixations.

The high rate of corrected screens was due to multiple elements on the screen, the viewing of which consisted of highly complex scan paths requiring frequent minor corrections of fixation positions falling on the wrong side of the AOI boundary. The researchers documented their repairs on an action level (e.g., shifting all fixations on a screen upward). The interrater agreement on the repair action (or lack of action) was $87.2 \%$. 


\section{Statistical analyses}

Descriptive analyses were carried out with analysis of variance (ANOVA). Due to the large between-subject variance, fixation times were analyzed both in absolute values (seconds) and as proportions to overall screen viewing time. However, in the SEM modeling, only absolute values were applied to enable reading skill measures to explain the between-subject variance in fixation times.

The goal of SEM modeling is to explain the relationships between measured and latent variables and the relationships among latent variables. The model building began by examining whether there was evidence for two latent factors corresponding to the easy and difficult questions. To this end, the easy and difficult factor models were tested against the one-factor model separately for accuracy, efficiency, and fixation times for relevant (FixRel) and irrelevant (FixIrrel) paragraphs. Likewise, the second-order factor (Fix) captured the highly correlated first-order factor of FixIrrel and FixRel.

To prevent multicollinearity due to high correlations between cognitive measures (except self-evaluated prior knowledge; see Appendix), a common latent factor (i.e., the g-factor) for cognitive measures was specified. Then, modification indices indicated whether the residual of a certain cognitive measure was associated with outcome or process measures over the g-factor, in which case, the specific factor for the residual was set. This allowed the residuals to directly predict outcome and process measures. The entire model was then specified by regressing the identified factors to the outcome measures (accuracy or efficiency) and the second-order factor of fixation (Fix) on the g-factor.

All estimations were made using the Mplus statistical package, version 8.3. Missing values were assumed to be randomly missing. To address possible deviations from normal distributions, full information maximum likelihood methods with robust standard error and chi-square test values were used in the estimation. In exceptional cases, the weighted least square mean and variance adjusted (WLSMV) method was used when testing the two-factor model against the one-factor model for the accuracy measure because this measure had only two (easy questions) or three categories (difficult questions). The model fit was evaluated with the chi-square test value, root mean square error of approximation (RMSEA), comparative fit index (CFI), Tucker-Lewis index (TLI), and standardized root mean square residual (SRMR). The cutoff values for a well-fitted model were a nonsignificant chi-square test value, RMSEA $<0.06, \mathrm{CFI}$ and TLI close to 0.95 , and SRMR $<0.08$ ( $\mathrm{Hu} \&$ Bentler, 1999; Muthén, 1998-2004).

\section{Results}

\section{Descriptive analyses}

Table 1 presents the descriptive statistics for the participants according to the identified study groups. Overall, in terms of outcome and process measures, control participants (C) and those with attention difficulties (AD) showed somewhat higher 
accuracy and efficiency in the information searching tasks and shorter fixation times on both irrelevant and relevant paragraphs than those with reading difficulties (RD) and those with comorbid reading and attention difficulties (CM). However, not all comparisons were significant after Bonferroni corrections. The same tendency was present in the cognitive measures, in which CM seemed to consistently show the lowest scores. Notably, all groups spent longer viewing relevant paragraphs than irrelevant paragraphs (in particular, the answer area in difficult questions), thus showing evidence for task-oriented reading. ${ }^{1}$

\section{Factor analysis}

To test whether the easy and difficult questions tap into different skills and processes, a two-factor solution was compared against a one-factor solution for all four outcome and process measures - that is, accuracy, efficiency, and fixation time on relevant and irrelevant paragraphs.

For the accuracy measure, the two-factor model did not fit the data better than the one-factor model, $\chi^{2}(1)=1.04,=0.307$. In the two-factor model, the factors were highly correlated, $r=.95$. For the efficiency measure, the two-factor model fit the data better than the one-factor model, $\chi^{2}(1)=6.92, p=.009$, and the two factors showed high correlation, $r=.78$.

For fixation time on the relevant paragraph, the two-factor model fit the data better than the one-factor model, $\chi^{2}(1)=81.61, p<.001$, and the factors showed high correlation, $r=.81$. For fixation time on the irrelevant paragraph, the two-factor model did not fit the data better than the one-factor model, $\chi^{2}(1)=3.33, p=.068$, but again, the factors of the two-factor model showed high correlation, $r=.97$. Despite only partial support being obtained for easy and difficult factors, two sums corresponding to easy and difficult questions were calculated for the four measures due to the desire to reduce the model complexity. This reduction is needed to fulfill the requirement of sample size relative to model complexity (Wolf et al., 2013).

\section{Accuracy model}

All of the cognitive measures loaded on the g-factor, with the standardized beta coefficient $\left(\beta^{\prime}\right)$ ranging from 0.39 for RAN letters to 0.71 for reading fluency (see Fig. 2). In the final model (see Fig. 2), a higher score on the g-factor predicted a directly and strongly higher score on the accuracy factor $\left(\beta^{\prime}=0.82, R^{2}=0.67\right)$. Higher scores on the $\mathrm{g}$-factor also predicted lower scores on the fixation factor $\left(\beta^{\prime}=\right.$ -0.37), i.e., shorter paragraph viewing times, on which fixation times on both irrelevant $\left(\beta^{\prime}=0.74\right)$ and relevant $\left(\beta^{\prime}=0.87\right)$ paragraphs were strongly loaded.

\footnotetext{
1 There was a significant task number and task difficulty interaction, indicating that over the course of the experiment, the students became more efficient in answering the what questions (from 0.011 to 0.022 scores per second) but not the why questions (from 0.016 to 0.015 scores per second), $F(4,572)=19.74$, $p<.001, \eta_{p}{ }^{2}=0.121$.
} 


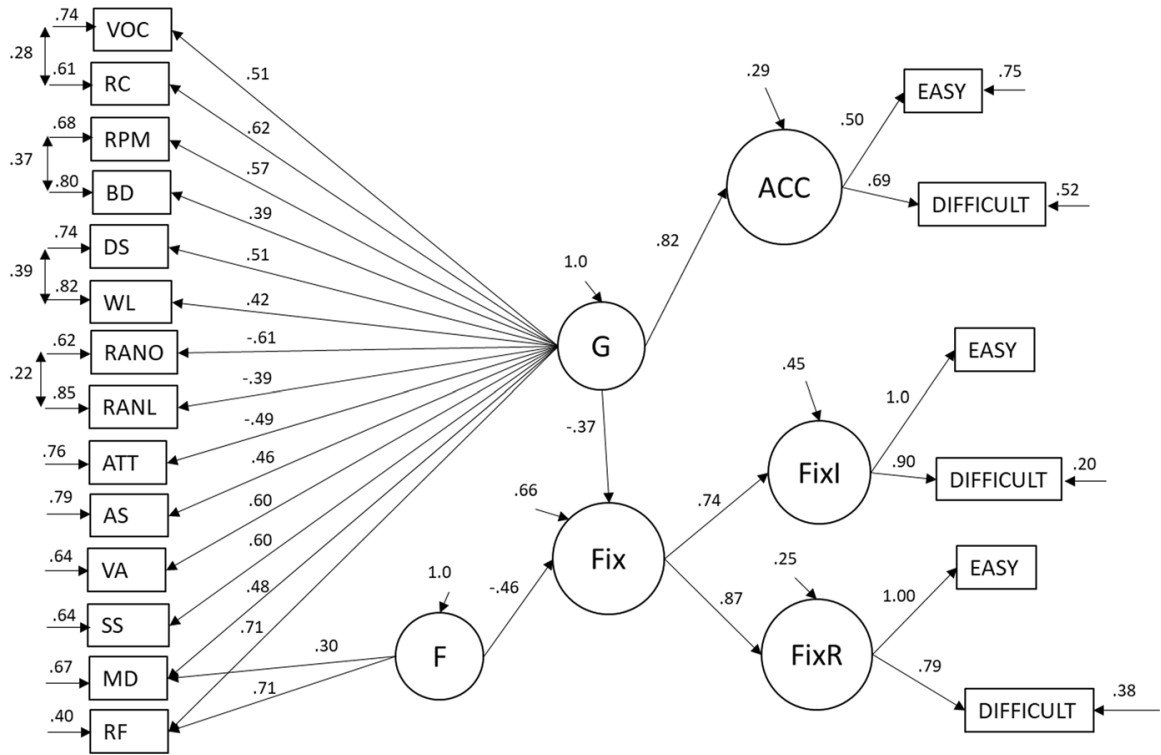

Fig. 2 Structural equation model for accuracy in task-oriented reading. The standardized beta values are shown in this figure. The nonconnecting arrows are residuals. Abbreviations: VOC = vocabulary; $\mathrm{RC}=$ reading comprehension; RPM = Raven, $\mathrm{BD}=$ block design; $\mathrm{DS}=$ digit span; $\mathrm{WL}=$ word list interference; RANO = RAN objects; RANL = RAN letters; ATT = attention difficulties; AS = animal sorting; $\mathrm{VA}=$ visual attention; $\mathrm{SS}=$ symbol search; $\mathrm{MD}=$ memory for designs; $\mathrm{RF}=$ reading fluency; $\mathrm{G}=$ g-factor; F = specific factor; Fix = fixation time; FixR = fixation time on the relevant paragraph; FixI = fixation time on the irrelevant paragraph; $\mathrm{ACC}=$ accuracy in task-oriented reading

As expected, poor reading fluency predicted longer fixation times via the specific factor $\mathrm{F}\left(\beta^{\prime}=-0.32\right)$, while the association from memory to design task to fixation via the specific factor $F$ is not readily interpretable. Neither of the indirect paths (derived by multiplying the coefficients paths) of theoretical interest, that is, neither the effect of the g-factor via fixation to accuracy nor that from the reading fluency factor via fixation to accuracy, was significant. Together, these results indicate that accuracy in task-oriented reading is mostly determined by general cognitive ability, not by viewing times, which were, in turn, somewhat shorter for students with high cognitive ability and reading fluency.

The model building progressed as follows: accuracy and fixation factors were regressed on the g-factor. Reading fluency and memory for the design loaded on an additional specific factor, F, which did not correlate with the g-factor. This made it possible to add the specific association needed in the model, independent from the g-factor; that is, fixation was regressed on this specific factor. The model needed four residual covariances between block design and the Raven matrices, between word list interference and digit span, between vocabulary and reading comprehension, and between RAN objects and RAN letters. Note that despite these pairs coherently representing underlying cognitive constructs according to modification indices, they were not associated with process and outcome measures over and above the g-factor. 


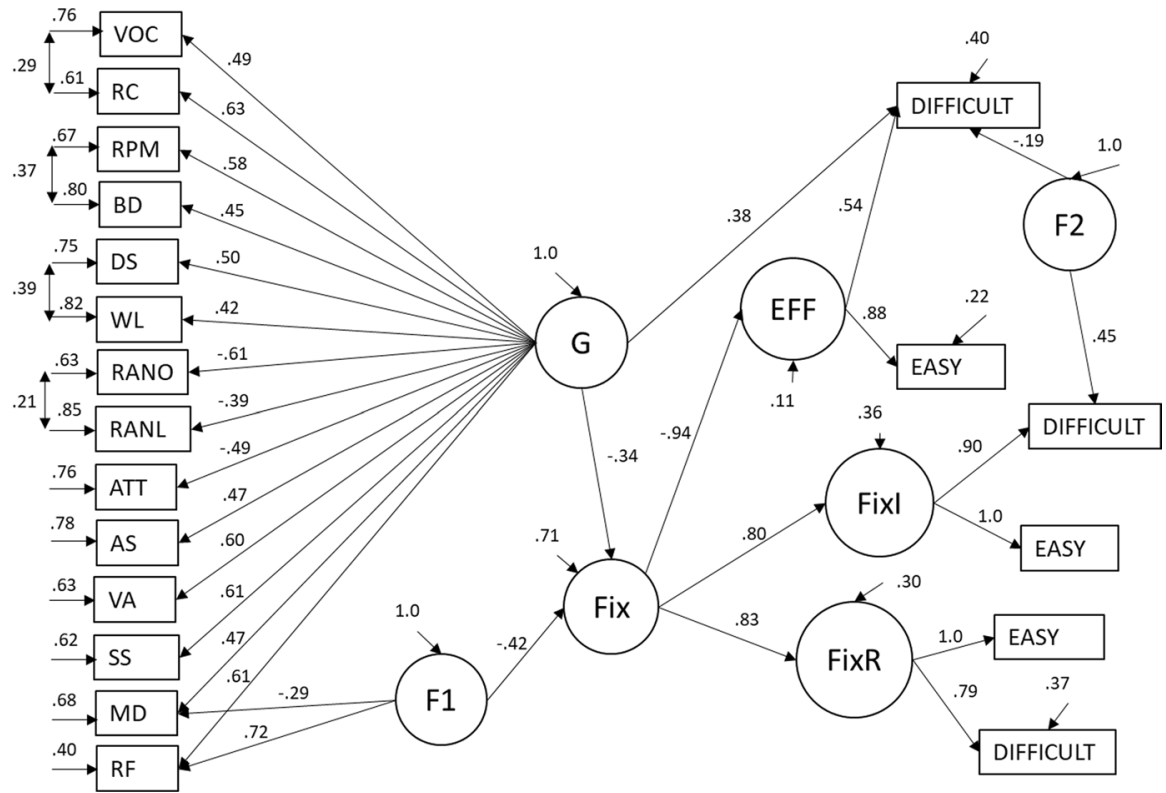

Fig. 3 Structural equation model for efficiency of task-oriented reading. Abbreviations in addition to those listed in Fig. 2: F1 = specific factor; F2 = specific factor 2; EFF = efficiency

The two small, negative residual variances were fixed to zero in the final accepted model, which fit well enough to the data: $\chi^{2}(160)=249.72 ;<0.001$; RMSEA $=$ $0.058, \mathrm{CFI}=0.92 ; \mathrm{TLI}=0.91 ; \mathrm{SRMR}=0.067$. Even though the chi-square test value was statistically significant and the CFI and TLI were lower than required for a well-fitted model, the modification indices were small, showing that no extra parameters were needed for the model. This is also shown by the small RMSEA $(<0.06)$ and SRMR $(<0.08)$ values. In the final model shown in Fig. 2, the standardized parameter coefficients are all statistically significant.

\section{Efficiency model}

In the final model (see Fig. 3), the observed variable of efficiency in easy questions $\left(\beta^{\prime}=0.88, R^{2}=0.77\right)$ loaded more strongly than the observed variable of efficiency in difficult questions $\left(\beta^{\prime}=0.54, R^{2}=0.29\right)$ on the first-order factor of efficiency. First-order factors fixation times on both irrelevant $\left(\beta^{\prime}=0.80, R^{2}=0.64\right)$ and relevant $\left(\beta^{\prime}=0.83, R^{2}=0.67\right)$ paragraphs loaded strongly on the second-order factor of fixation time.

Lower scores on the fixation factor then very strongly predicted higher scores on the efficiency factor $\left(\beta^{\prime}=-0.94, R^{2}=0.89\right)$. Notably, the g-factor directly, albeit weakly, predicted the efficiency of the difficult questions by $\beta^{\prime}=0.38\left(R^{2}=0.14\right)$. As expected, poor reading fluency predicted longer fixation times $\left(\beta^{\prime}=-0.42\right)$. The negligible specific association from memory to design to fixation was not readily 
interpretable. There were two significant indirect effects from the g-factor via fixation to efficiency $\left(\beta^{\prime}=0.32, p<.001, R^{2}=0.10\right)$ and from the reading fluency factor (F1) via fixation to efficiency $\left(\beta^{\prime}=0.39, p<.001, R^{2}=0.15\right)$. Additionally, longer residual fixation time on irrelevant paragraphs predicted slightly poorer efficiency in difficult questions $\left(\beta^{\prime}=-0.19, R^{2}=0.04\right)$. The results indicate that efficiency in taskoriented reading is mostly determined by viewing time, which also largely mediates the influence of reading fluency and general cognitive ability on efficiency. However, efficiency in difficult questions is also directly explained by higher cognitive ability.

The model building progressed as follows: Efficiency was regressed on fixation, and fixation was regressed on the g-factor. Similar to the accuracy model, reading fluency and memory for designs loaded on an additional specific factor (F1) that did not correlate with the g-factor. Fixation was regressed on this specific factor. Efficiency in the difficult question was regressed on the g-factor. A specific factor (F2) capturing the association between fixation times on irrelevant paragraphs and efficiency in the difficult question was added. The model needed six residual covariances between reading comprehension and vocabulary, between block design and the Raven matrices, between word list interference and digit span, and between RAN objects and RAN letters.

The small, negative residual variances were fixed to zero in the final accepted model, which fits well to the data: $\chi^{2}(160)=231.07 ; \mathrm{p}<0.001$; RMSEA $=0.052$; $\mathrm{CFI}=0.94$; TLI $=0.93$; SRMR $=0.068$. Even though the chi-square test value was statistically significant and the TLI was slightly lower than required for a well-fitted model, the modification indices were small, showing that no extra parameters were needed for the model. This is also shown by the high CFI $(>0.90)$, small RMSEA $(<0.08)$, and SRMR $(<0.08)$ values. In the final model shown in Fig. 3, the standardized parameter coefficients are all statistically significant.

\section{Supplementary analyses}

We further studied whether efficient readers are more selective in their reading, that is, whether they show a larger relevancy effect and perhaps respond differently to paragraph order. To this end, a full-factorial repeated-measures ANOVA was run for absolute fixation times proportional to screen viewing time. This analysis included two-level factors of question type (easy and difficult), paragraph order (relevant to irrelevant and irrelevant to relevant), and paragraph type (relevant and irrelevant) and included efficiency tertile group as a between-subject factor. The critical interaction of the relevancy and efficiency groups was not significant in absolute values, $F(2,155)=3.016, p=.052, \eta_{p}{ }^{2}=0.037$, but it was highly significant in proportional values of screen viewing time, $F(2,155)=31.983, p<.001, \eta_{p}{ }^{2}=0.292$. Panel (a) in Fig. 4 shows how efficient task-oriented readers allocated much more of their viewing time to relevant paragraphs than to irrelevant paragraphs.

Paragraph order interacted strongly with relevance in both absolute values, $\mathrm{F}(2$, $155)=175.3, p<.001, \eta_{p}{ }^{2}=0.531$, and proportional values, $F(2,155)=132.2$, $p<.001, \eta_{p}{ }^{2}=0.460$. Panel (b) in Fig. 4 shows how fixation times for relevant 

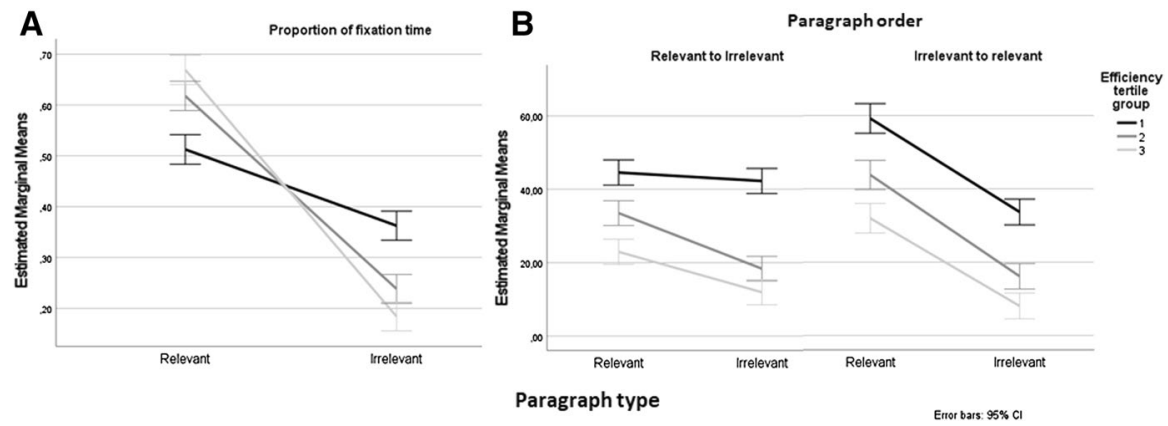

Fig. 4 Results of the supplementary analyses of fixation times

paragraphs were inflated when preceded by an irrelevant paragraph. Additionally, the three-level interaction of efficiency group $\times$ order $\times$ relevancy was significant in absolute values, $F(2,155)=8.094, p<.001, \eta_{p}{ }^{2}=0.095$, but not in proportional values, $F(2,155)=2.911, p=.057, \eta_{p}{ }^{2}=0.036$, resulting from a tendency of inefficient readers to view an irrelevant paragraph for a particularly long time when it was presented after a relevant paragraph.

Panel (a) shows the fixation times proportional to the screen viewing time, and Panel (b) shows the fixation times in relation to paragraph order.

\section{Discussion}

To unravel the generic factors underlying task-oriented reading skill, associations between readers' cognitive skills and viewing times of relevant and irrelevant paragraphs on task-oriented reading outcomes (accuracy and efficiency) were analyzed by SEM on a large sample of sixth-grade students, among whom reading $(\mathrm{n}=23)$ and attention difficulties $(n=28)$ or their comorbidity $(n=24)$ were overrepresented relative to the control group $(\mathrm{n}=89)$.

Overall, the students performed better on the easy questions than the difficult questions and spent considerably more time viewing relevant paragraphs than irrelevant paragraphs, which was mostly due to specifically viewing the answers. Proportional to the students' overall screen viewing time, unlike less efficient readers, more efficient readers allocated more attention to relevant information and less attention to irrelevant information.

These results are in accordance with the previous understanding that having a specific task leads to selective reading, and this tends to be the case more for skilled task-oriented readers than for unskilled readers (Cerdán \& Vidal-Abarca, 2008; Cromley \& Azevedo, 2009; Hautala et al., 2018; Kaakinen et al., 2015; León et al., 2019; Salmerón et al., 2017; Yeari et al., 2015). 


\section{Reading strategies}

First, whether efficiency in task-oriented reading is obtained due to a strategic decision to read only the relevant paragraphs, as cued by an informative heading, was studied. The fixation times on irrelevant and relevant paragraphs formed a strong viewing time factor, indicating that students who spent little time viewing irrelevant paragraphs read relevant paragraphs faster. ${ }^{2}$ Supplementary analyses further specified that students spent the same amount of time reading the irrelevant paragraph irrespective of whether it came located first or second on the screen, likely to ensure it did not contain relevant information.

These results suggest a continuous regulation of one's reading depth according to local variations in text relevancy (Yeari et al., 2015; Hautala et al., 2018; Kaakinen et al., 2015; Rouet, 2006; Salmerón et al., 2015) rather than making a clear-cut strategic decision about which paragraph to read. These findings are highly compatible with the TRACE model (Rouet, 2006) and its extensions (RESOLV: Rouet et al., 2017 ) in the sense that reading is continuously controlled by goal-oriented schemas and representations.

Second, it was hypothesized that while high accuracy could be obtained with a thorough reading of both paragraphs, obtaining high efficiency would require relying on a selective reading strategy. In accordance with this prediction, viewing times only slightly explained the accuracy (8\%), indicating that the correct answer could also be extracted through either a swift or a prolonged reading of the texts. Instead, efficiency was explained almost solely by the viewing time factor (88\%). These results provide further support for efficiency being an important and separate construct to accuracy in basic informational tasks (Soederberg Miller, 2009). Our results also indicate that reading strategies are more central to obtaining high efficiency than to being accurate.

How might the continuous regulation of reading depth operate, leading to high differences in efficiency? Typically, people read through a text first to obtain an overview and then return to the most relevant part of the text (Hautala et al., 2018; Kaakinen et al., 2015; León et al., 2019; Yeari et al., 2015). This strategy is typically associated with comprehension benefits (Cerdán et al., 2009; Rouet et al., 2003). It does not require inhibiting oneself from a response (Wilson et al., 2003) to read the whole text presented. However, people seem to differ considerably in how they construct a text representation (see, e.g., Salmerón et al., 2017). Efficient readers seem to rely more on preexisting schemas of task and text structure (Cataldo \& Oakhill, 2000) - that is, on the assumption that only a small piece of information is relevant (also within a relevant paragraph) and that it is unlikely to be scattered across both paragraphs. Instead, less efficient readers may lack such schemas and, consequently, may be more attuned to exploring the text extensively. Our supplementary analyses of fixation times provide some support for this stance. Having already read the

\footnotetext{
2 At the extreme, for the easy questions, the most efficient one-third of the students viewed irrelevant paragraphs for $8 \mathrm{~s}$ on average and relevant paragraphs for $23 \mathrm{~s}$.
} 
answer in the preceding relevant paragraph did not help the inefficient readers spend less time on reading the subsequent irrelevant paragraph.

Finally, the highly structured task with several repetitions induced some learning: The students doubled their efficiency in answering the easy fact-finding tasks, but such development was not observed with more difficult tasks. During the course of the experiment, students probably started to learn and anticipate that the answer would always be found in a single location. When the task was easy, this learning was directly reflected in efficiency. Instead, efficiency in difficult tasks seems to be more dependent on the students' ability to semantically encode the information. We will return to this point in the next section when discussing the role of the g-factor in task-oriented reading.

\section{Cognitive skills and task-oriented reading}

Third, the association between cognitive skills and task-oriented reading was studied. General cognitive ability was expected to explain accuracy, especially for difficult questions, while reading fluency was expected to explain fixation times. Thus, it was of interest to determine whether residual variability in specific cognitive skills, such as reading comprehension or attention problems, would explain some additional variance in viewing times, accuracy, and efficiency.

Control students and those with only attention difficulties performed somewhat better in task-oriented reading, particularly with difficult questions, than students with reading difficulties and comorbid attention and reading difficulties, who also performed less well than the control participants in several cognitive measures. Consequently, a strong g-factor was identified from the cognitive measures on which reading skills and attention difficulties were strongly loaded (Laasonen et al., 2020). The g-factor directly explained $67 \%$ of the accuracy (cf. Moehring et al., 2016), indicating the high importance of general cognitive ability in locating and encoding relevant semantic content. The mediation effects from cognitive skills to efficiency via viewing times were modest, as the g-factor explained $10 \%$ of the overall efficiency, and reading fluency explained $15 \%$. Task difficulty induced multidimensionality in explaining the efficiency outcome, as the g-factor directly explained efficiency in the more difficult questions (14\% of variance). These results indicate that high reading fluency and general cognitive ability explain efficiency only modestly; therefore, reading strategies should be specifically targeted in reading instruction. This view is in line with a large body of literature demonstrating that explicit reading comprehension and strategy instruction is highly effective (see, e.g., Berkeley et al., 2010).

The results of the present study indicate that general cognitive ability plays an important role among school-age learners (i.e., sixth grade, at approximately 12 years old) in obtaining the right solutions for given problems (cf. Laasonen et al., 2020; Moehring et al., 2016). It thus seems likely that cognitive skills typically develop concurrently, so gross deviations between, for example, verbal and visuospatial skills are rare (Ramsden et al., 2011). However, in our study, it is possible that the latent g-factor well captured the common variance in basic cognitive skills, but these skills may not be highly correlated with higher-level literacy skills. Previous 
studies (Mañá et al., 2017; Vidal-Abarca et al., 2010) have shown that complex taskoriented reading places special demands on metacognitive monitoring in adolescents. In addition, Kanniainen et al. (2019) found only a 14\% explanatory power for nonverbal reasoning in explaining overall internet reading proficiency, which also consists of higher-level literacy activities such as reading multiple documents and synthesizing information into short written text. In line with this, the less strategic aspect of performance in our study (i.e., accuracy) was better predicted by general cognitive ability than the presumably more strategic skill of efficiency was.

The present study results add to our knowledge about the generic cognitive mechanisms that underlie task-oriented reading. First, general cognitive ability seems to specifically support the semantic comprehension of text and its maintenance in working memory, which is crucial for obtaining high accuracy in task-oriented reading (Moehring et al., 2016). Instead, the selection of what to read and to what depth, which is crucial for efficiency, may depend on the metacognitive control of behavior and trained expertise, as it is potentially a more malleable aspect of task-oriented reading (Kempe et al., 2011). Supportive of this stance are past findings that intelligence is not a significant predictor of response to reading interventions (Stuebing et al., 2009) and that explicit reading comprehension and strategy instruction are highly effective (Berkeley et al., 2010).

\section{Pedagogical implications}

Regarding the mastery of the relatively simple task-oriented reading tasks studied here, the present results indicate that learning difficulties pose no additional burden other than what is predicted by general cognitive ability and reading fluency. Taskoriented reading involves multiple aspects that require explicit reflection and practice, such as what the minimum requirements of the task at hand are, how and where one would obtain the required information, and what to do with the information.

In practice, such evaluation and control routines (Rouet, 2003) may become an integral part of one's literacy skills. The results of the present study suggest that students with relatively low cognitive skills may also obtain good efficiency in taskoriented reading. However, the results also indicate that low cognitive ability poses a greater challenge for comprehension than for efficient reading. Therefore, basic taskoriented reading skills should first be learned through easy fact-finding tasks before progressing to tasks that require more semantic integration and interpretation.

Finally, students' apparent inability to strategically choose not to read an irrelevant paragraph raises concerns about the quality and scope of information literacy education in elementary schools in Finland, even though the country has a highly competent education system (OECD, 2019). On this basis, it is justified to suspect that task-oriented reading requires more educational attention on a global scale.

\section{Limitations}

The results of the present study may be limited to relatively simple forms of task-oriented reading. For example, cues about the relevance of the paragraphs were directly 
given in titles in a keyword-like manner, and the answers to easy questions were simple facts, such as numbers. This contrasts with previous research on more complex taskoriented reading requiring, for example, writing synthesized summaries of information gathered from multiple documents (see, e.g., Kanniainen et al., 2019). Specific cognitive skills and previous knowledge may be more important in such complex literacy activities. Relatedly, the present study was conducted with adolescents with and without learning disabilities. This limits the ability to draw strong conclusions concerning the theoretical models of task-oriented reading, which are founded on data collected mostly from adolescents or adult participants with no such disabilities. For instance, in the tasks studied here, most adults might be able to strategically choose not to read irrelevant paragraphs.

The process of continuously regulating one's reading depth according to text relevancy needs to be further examined. At the micro level, this process might be modeled as a continuous process of successive fixation durations and scanpaths as a function of word and sentence relevancy. However, due to the use of a small font size, this present study's dataset is not easily suited for such a precise analysis. Instead, the present dataset may be further used to model individual differences in macrolevel reading strategies. However, such a study would first need to handle several data processing challenges, such as how to separate skimming and first-pass reading. In addition, future studies should investigate the role of children's task model quality on their task-oriented reading (Ayroles et al., 2021) and should also consider including the time spent on reading the task assignment as a part of the efficiency measure.

The descriptive and supplementary analyses revealed several group and conditional differences. According to the SEM results, such specific effects (e.g., the difference between easy and difficult tasks and specific cognitive skills) were small compared to more general interrelations in the data (e.g., g-factor and overall viewing times). This present study demonstrates that SEM can be used to detect generic factors that underlie purposeful reading that may easily go unnoticed if only traditional analyses are conducted.

\section{Conclusions}

According to the present study results, (a) general cognitive abilities contribute strongly to comprehension during task-oriented reading and (b) the continuous regulation of one's reading depth according to local variations in text relevancy is a default strategy for obtaining high efficiency in task-oriented reading. Finally, students with learning difficulties performed well in efficiently finding answers to simple fact-finding tasks. However, they had difficulty in providing correct answers to more difficult tasks, which is expected given their somewhat lower general cognitive ability. However, all students, irrespective of their general cognitive ability, seemed able to learn more efficient reading strategies.

\section{Appendix}

See table 2 


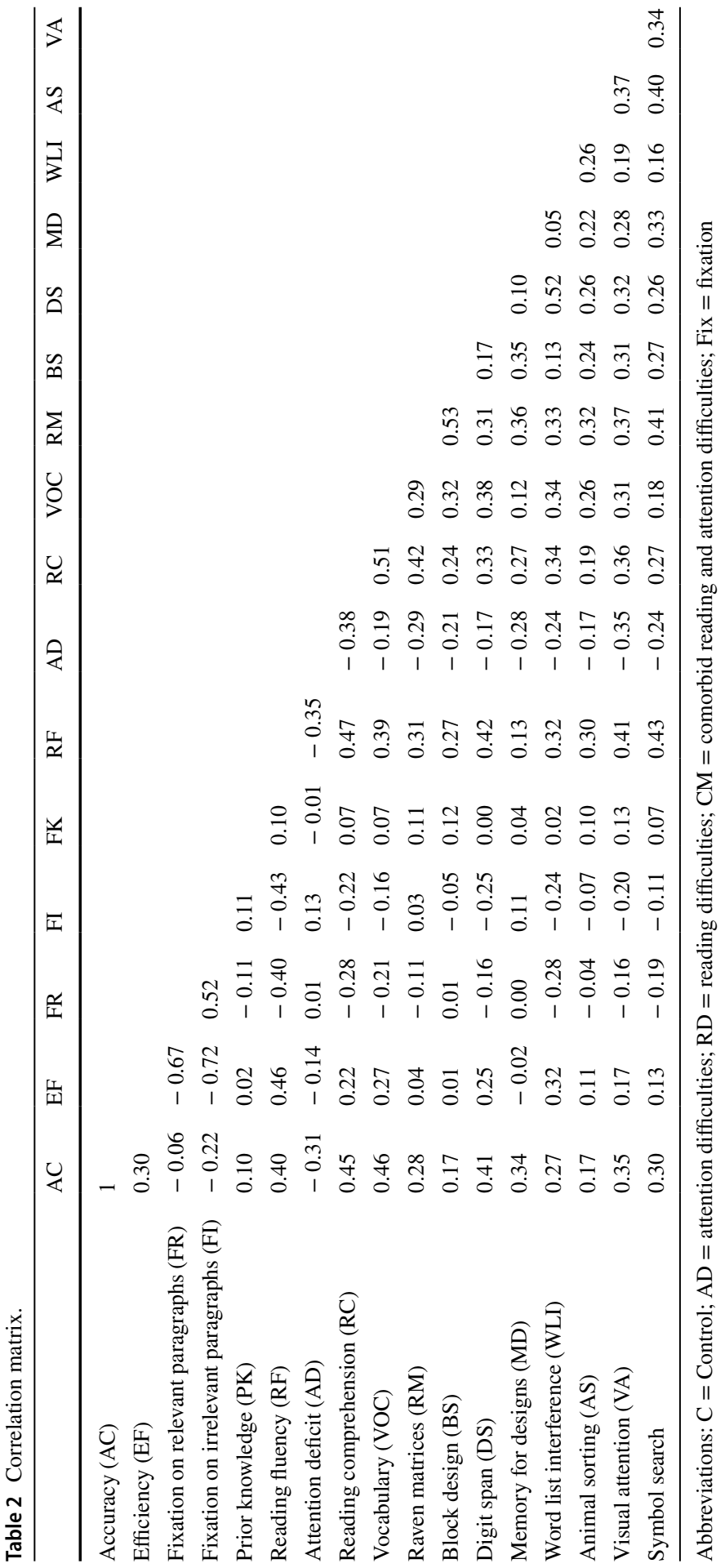


Acknowledgements The authors also want to thank Sini Hjelm for organising the data collection, and all of the research colleagues, research assistants, and students involved in the research project, and the anonymous reviewers for their valuable comments.

Funding Open Access funding provided by University of Jyväskylä (JYU). This research was funded by Academy of Finland with grant 274022 toPaavo Leppänen and working of first author for years 20182021 was supported by grants 317030 to Jarkko Hautala

\section{Declarations}

Ethical Approval Ethics approval was received from Ethical Board of University of Jyväskylä. Informed consent was derived from participants and their caregivers.

Informed Consent Informed consent was derived from participants and their caregivers. All the authors have approved the submission of this manuscript. Access to required parts of data and code may be provided with a reasonable request made to the authors. If open access option will be selected, this work is licensed under a CC BY 4.0 license or other license granting green open access publishing after possible embargo period.

Open Access This article is licensed under a Creative Commons Attribution 4.0 International License, which permits use, sharing, adaptation, distribution and reproduction in any medium or format, as long as you give appropriate credit to the original author(s) and the source, provide a link to the Creative Commons licence, and indicate if changes were made. The images or other third party material in this article are included in the article's Creative Commons licence, unless indicated otherwise in a credit line to the material. If material is not included in the article's Creative Commons licence and your intended use is not permitted by statutory regulation or exceeds the permitted use, you will need to obtain permission directly from the copyright holder. To view a copy of this licence, visit http://creativecommons.org/licen ses/by/4.0/.

\section{References}

Alloway, T. P., \& Gregory, D. (2013). The predictive ability of IQ and working memory scores in literacy in an adult population. International Journal of Educational Research, 57, 51-56

Anmarkrud, Ø., Brante, E. W., \& Andresen, A. (2018). Potential processing challenges of Internet use among readers with dyslexia. In J. L. G. Braasch, I. Bråten, \& M. T. McCrudden (Eds.), Handbook of multiple source use. Routledge

Ayroles, J., Potocki, A., Ros, C., Cerdán, R., Britt, M. A., \& Rouet, J. F. (2021). Do you know what you are reading for? Exploring the effects of a task model enhancement on fifth graders' purposeful reading. Journal of Research in Reading, 44(4), 837-858

Bar-Zvi Shaked, K., Shamir, A., \& Vakil, E. (2020). An eye tracking study of digital text reading: a comparison between poor and typical readers. Reading and Writing, 33, 1925-1944

Ben-Yehudah, G., \& Brann, A. (2019). Pay attention to digital text: The impact of the media on text comprehension and self-monitoring in higher-education students with ADHD. Research in developmental disabilities, 89, 120-129

Ben-Yehudah, G., Hautala, J., Padeliadu, S., Antoniou, F., Petrová, Z., Leppänen, P., \& Barzillai, M. (2018). Affordances and challenges of digital reading for individuals with different learning profiles. In M. Barzillai, J. Thomson, S. Schroeder, \& van der Broek (Eds.), Learning to read in a digital world (pp. 121-140). John Benjamins

Berkeley, S., Scruggs, T. E., \& Mastropieri, M. A. (2010). Reading comprehension instruction for students with learning disabilities, 1995-2006: A meta-analysis. Remedial and Special Education, 31(6), 423-436

Britt, M. A., Rouet, J. F., \& Durik, A. M. (2017). Literacy beyond text comprehension: A theory of purposeful reading. Routledge 
Cataldo, G. M., \& Oakhill, J. (2000). Why are poor comprehenders inefficient searchers? An investigation into the effects of text representation and spatial memory on the ability to locate information in text. Journal of educational psychology, 92(4), 791

Cerdán, R., Pérez, A., Vidal-Abarca, E., \& Rouet, J. F. (2019). To answer questions from text, one has to understand what the question is asking: differential effects of question aids as a function of comprehension skill. Reading and Writing, 32(8), 2111-2124

Cerdán, R., \& Vidal-Abarca, E. (2008). The effects of tasks on integrating information from multiple documents. Journal of educational psychology, 100(1), 209

Cerdán, R., Vidal-Abarca, E., Martinez, T., Gilabert, R., \& Gil, L. (2009). Impact of question-answering tasks on search processes and reading comprehension. Learning and Instruction, 19(1), 13-27

Cohen, A. L. (2013). Software for the automatic correction of recorded eye fixation locations in reading experiments. Behavior Research Methods, 45(3), 679-683. https://doi.org/10.3758/ s13428-012-0280-3.

Coiro, J. (2011). Predicting reading comprehension on the Internet: Contributions of offline reading skills, online reading skills, and prior knowledge. Journal of literacy research, 43(4), 352-392

Cromley, J. G., \& Azevedo, R. (2009). Locating information within extended hypermedia. Educational Technology Research and Development, 57(3), 287-313

Denckla, M. B., \& Rudel, R. G. (1976). Rapid 'automatized' naming (RAN): Dyslexia differentiated from other learning disabilities. Neuropsychologia, 14(4), 471-479

Eklund, K., Torppa, M., Aro, M., Leppänen, P. H., \& Lyytinen, H. (2015). Literacy skill development of children with familial risk for dyslexia through grades 2, 3, and 8. Journal of Educational Psychology, 107(1), 126

Hart, B., \& Risley, T. R. (1995). Meaningful differences in the everyday experience of young American children. Paul H Brookes Publishing

Hautala, J., Kiili, C., Kammerer, Y., Loberg, O., Hokkanen, S., \& Leppänen, P. H. T. (2018). Sixth graders' evaluation strategies when reading Internet search results: an eye-tracking study. Behaviour \& Information Technology, 37(8), 761-773. https://doi.org/10.1080/0144929X.2018.1477992.

Hautala, J., Loberg, O., Azaiez, N., Taskinen, S., Tiffin-Richards, S. P., \& Leppänen, P. H. (2019). What information should I look for again? Attentional difficulties distracts reading of task assignments. Learning and Individual Differences, 75, 101775

Holopainen, L., Kairaluoma, L., Nevala, J., Ahonen, T., \& Aro, M. (2004). Lukivaikeuksien seulontatesti nuorille ja aikuisille [Dyslexia screening test for youth and adults]. Niilo Mäki Institute

Hu, L., \& Bentler, P. M. (1999). Cutoff criteria for fit indexes in covariance structure analysis: Conventional criteria versus new alternatives. Structural Equation Modeling, 6, 1-55

Jensen, A. R. (1998). The g factor: The science of mental ability. Praeger

Kaakinen, J. K., Lehtola, A., \& Paattilammi, S. (2015). The influence of a reading task on children's eye movements during reading. Journal of Cognitive Psychology, 27(5), 640-656

Kanerva, K., Kiistala, I., Kalakoski, V., Hirvonen, R., Ahonen, T., \& Kiuru, N. (2019). The feasibility of working memory tablet tasks in predicting scholastic skills in classroom settings. Applied Cognitive Psychology, 33(6), 1224-1237

Kanniainen, L., Kiili, C., Tolvanen, A., Aro, M., \& Leppänen, P. H. (2019). Literacy skills and online research and comprehension: struggling readers face difficulties online. Reading and Writing, 32(9), 2201-2222

Kempe, C., Eriksson-Gustavsson, A. L., \& Samuelsson, S. (2011). Are there any Matthew effects in literacy and cognitive development? Scandinavian Journal of Educational Research, 55(2), 181-196

Kiili, C., Leu, D. J., Utriainen, J., Coiro, J., Kanniainen, L., Tolvanen, A. ... Leppänen, P. H. (2018). Reading to learn from online information: Modeling the factor structure. Journal of Literacy Research, 50(3), 304-334

Klenberg, L., Jämsä, S., Häyrinen, T., Lahti-Nuuttila, P., \& Korkman, M. (2010). The Attention and Executive Function Rating Inventory (ATTEX): Psychometric properties and clinical utility in diagnosing ADHD subtypes. Scandinavian Journal of Psychology, 51(5), 439-448

Korkman, M., Kirk, U., \& Kemp, S. L. (2008). NEPSY-II: Lasten neuropsykologinen tutkimus. [NEPSYII: A Developmental Neuropsychological Assessment]. Psykologien Kustannus Oy

Korstanje, J. (2021, June 27). "Structural Equation Modelling: A comprehensive overview of Structural Equation Modeling with a full walkthrough of an example using both R and Python." In Towards Data Science. https://towardsdatascience.com/structural-equation-modeling-dca298798f4d 
Laasonen, M., Lahti-Nuuttila, P., Leppämäki, S., Tani, P., Wikgren, J., Harno, H. ... Cousineau, D. (2020). Project DyAdd: Non-linguistic Theories of Dyslexia Predict Intelligence. Frontiers in human neuroscience, 14, 316

León, J. A., Moreno, J. D., Escudero, I., Olmos, R., Ruiz, M., \& Lorch, R. F. Jr. (2019). Specific relevance instructions promote selective reading strategies: evidences from eye tracking and oral summaries. Journal of Research in Reading, 42(2), 432-453

Lindeman, J. (1998). Allu-Ala-asteen lukutesti [Reading test for primary school]. University of Turku

Lorch, R., Lemarié, J., \& Grant, R. (2011). Signaling hierarchical and sequential organization in expository text. Scientific Studies of Reading, 15(3), 267-284

Mañá, A., Vidal-Abarca, E., \& Salmerón, L. (2017). Effect of delay on search decisions in a task-oriented reading environment. Metacognition and Learning, 12(1), 113-130

Martínez, T., Vidal-Abarca, E., Gil, L., \& Gilabert, R. (2009). On-line assessment of comprehension processes. The Spanish Journal of Psychology, 12(1), 308

McCrudden, M. T., \& Schraw, G. (2007). Relevance and goal-focusing in text processing. Educational psychology review, 19(2), 113-139

McCrudden, M. T., Magliano, J. P., \& Schraw, G. (2010). Exploring how relevance instructions affect personal reading intentions, reading goals, and text processing: A mixed methods study. Contemporary Educational Psychology, 35(4), 229-241

Moehring, A., Schroeders, U., Leichtmann, B., \& Wilhelm, O. (2016). Ecological momentary assessment of digital literacy: Influence of fluid and crystallized intelligence, domain-specific knowledge, and computer usage. Intelligence, 59, 170-180

Muthén, B. O. (1998-2004). Mplus Technical Appendices. Muthén \& Muthén

OECD. (2019). PISA 2018 Results: What Students Know and Can Do (Volume I). OECD

Packwood, S., Hodgetts, H. M., \& Tremblay, S. (2011). A multiperspective approach to the conceptualization of executive functions. Journal of clinical and experimental neuropsychology, 33(4), 456-470

Ramsden, S., Richardson, F. M., Josse, G., Thomas, M. S., Ellis, C., Shakeshaft, C. ... Price, C. J. (2011). Verbal and non-verbal intelligence changes in the teenage brain. Nature, 479(7371), 113-116

Raven, J. C.,J Court (1998). Raven's progressive matrices and vocabulary scales. Oxford pyschologists Press

Rindermann, H. (2007). The g-factor of international cognitive ability comparisons: The homogeneity of results in PISA, TIMSS, PIRLS and IQ-tests across nations. European Journal of Personality, 21(5), 667-706

Rouet, J. F. (2003). What was I looking for? The influence of task specificity and prior knowledge on students' search strategies in hypertext. Interacting with Computers, 15, 409-428

Rouet, J. F. (2006). The skills of document use: From text comprehension to Web-based learning. Psychology Press

Rouet, J. F., Britt, M. A., \& Durik, A. M. (2017). RESOLV: Readers' representation of reading contexts and tasks. Educational Psychologist, 52(3), 200-215

Rouet, J. F., Vidal-Abarca, E., Erboul, A. B., \& Millogo, V. (2001). Effects of information search tasks on the comprehension of instructional text. Discourse Processes, 31(2), 163-186

Salmerón, L., García, A., \& Vidal-Abarca, E. (2018). The development of adolescents' comprehension-based Internet reading activities. Learning and Individual Differences, 61, 31-39

Salmerón, L., Naumann, J., García, V., \& Fajardo, I. (2017). Scanning and deep processing of information in hypertext: an eye tracking and cued retrospective think-aloud study. Journal of Computer Assisted Learning, 33(3), 222-233

Salmerón, L., Vidal-Abarca, E., Martínez, T., Mañá, A., Gil, L., \& Naumann, J. (2015). Strategic decisions in task-oriented reading. The Spanish journal of psychology, 18, 1-10

Snow, C. (2002). Reading for Understanding: Toward an R\&D Program in Reading Comprehension. RAND Corporation

Soederberg Miller, L. M. (2009). Age differences in the effects of domain knowledge on reading efficiency. Psychology and aging, 24(1), 63

Stern, P., \& Shalev, L. (2013). The role of sustained attention and display medium in reading comprehension among adolescents with ADHD and without it. Research in developmental disabilities, 34(1), 431-439

Stine-Morrow, E. A., Miller, L. M. S., \& Hertzog, C. (2006). Aging and self-regulated language processing. Psychological bulletin, 132(4), 582 
Stuebing, K. K., Barth, A. E., Molfese, P. J., Weiss, B., \& Fletcher, J. M. (2009). IQ is not strongly related to response to reading instruction: A meta-analytic interpretation. Exceptional Children, 76(1), 31-51

Sung, Y. T., Wu, M. D., Chen, C. K., \& Chang, K. E. (2015). Examining the online reading behavior and performance of fifth-graders: evidence from eye-movement data. Frontiers in Psychology, 6, 665

Tawfik, A. A., Graesser, A., Gatewood, J., \& Gishbaugher, J. (2020). Role of questions in inquiry-based instruction: towards a design taxonomy for question-asking and implications for design.Educational Technology Research and Development,1-26

Vidal-Abarca, E., Mañá, A., \& Gil, L. (2010). Individual differences for self-regulating task-oriented reading activities. Journal of Educational Psychology, 102, 817-826

Vidal-Abarca, E., Salmerón, L., \& Mañá, A. (2011). Individual differences in task-oriented reading. In M. T. McCrudden, J. P. Magliano, \& G. Schraw (Eds.), Text relevance and learning from text (pp. 267-293). IAP Information Age Publishing

Wechsler, D. (2003). Wechsler intelligence scale for children-Fourth Edition. WISC-IV). The Psychological Corporation

Wilson, S. P., Kipp, K., \& Daniels, J. (2003). Task demands and age-related differences in retrieval and response inhibition. British Journal of Developmental Psychology, 21(4), 599-613

Wolf, E. J., Harrington, K. M., Clark, S. L., \& Miller, M. W. (2013). Sample size requirements for structural equation models: An evaluation of power, bias, and solution propriety. Educational and psychological measurement, 73(6), 913-934

Wolf, M. S., Curtis, L. M., Wilson, E. A., Revelle, W., Waite, K. R., Smith, S. G., \& Deary, I. C. (2012). Literacy, cognitive function, and health: results of the LitCog study. Journal of general internal medicine, 27(10), 1300-1307.

Wytek, R., Opgenoorth, E., \& Presslich, O. (1984). Development of a new shortened version of Raven's Matrices test for application rough assessment of present intellectual capacity within psychopathological investigation. Psychopathology, 17(2), 49-58

Yeari, M., van den Broek, P., \& Oudega, M. (2015). Processing and memory of central versus peripheral information as a function of reading goals: Evidence from eye-movements. Reading and Writing, 28(8), 1071-1097

Publisher's Note Springer Nature remains neutral with regard to jurisdictional claims in published maps and institutional affiliations. 